\title{
A EXPERIÊNCIA DO LABORATÓRIO DE DESIGN SOLIDÁRIO COM A ESCOLA DE SAMBA COROA IMPERIAL DA GRANDE CIDADE
}

\author{
Rodrigo Rocha Nogueira \\ Universidade Estadual Paulista "Júlio de Mesquita Filho", UNESP \\ rodrigoorocha_@outlook.com \\ Claudio Roberto y Goya \\ Universidade Estadual Paulista "Júlio de Mesquita Filho", UNESP \\ goyaclaudio@hotmail.com \\ Juliana Soares de Souza \\ Universidade Estadual Paulista "Júlio de Mesquita Filho", UNESP \\ soares.s.juliana@gmail.com \\ Douglas Eduardo Noronha Simão \\ Universidade Estadual Paulista "Júlio de Mesquita Filho", UNESP \\ nobregas_4@hotmail.com \\ Thamires Bueno da Rosa \\ Universidade Estadual Paulista "Júlio de Mesquita Filho", UNESP \\ tbr-bueno@hotmail.com
}

Resumo: Trata-se da apresentação de resultados e considerações acerca dos trabalhos desenvolvidos pelo Projeto de Extensão Universitária em Design, Laboratório de Design Solidário, Labsol, Instituição de Ensino Superior por meio da parceria com o Grêmio Recreativo Escola de Samba Coroa Imperial da Grande Cidade, para realizar os desfiles de carnaval de 2014 a 2016. A parceira do Labsol e a Coroa Imperial trouxe aos integrantes do Labsol a reflexão sobre o papel do Design e do designer permitiu uma rara experiência universitária, abarcando o ensino de design, a atividade projetual (em uma dimensão que partiu do brainstorn à produção em série) atividades de pesquisa, embarcando materiais, processos e métodos e a extensão universitária, aproximando a Universidade Pública e a Comunidade que a mantém.

Palavras-chave: Design de vestuário, Sustentabilidade, Carnaval, Labsol

Abstract: This is the presentation of results and considerations about the work developed by the University Extension Project Design, Laboratório de Design Solidário, Labsol, Higher Education Institution, next to two psychosocial care groups through income and job generation activities and the Guild Recreational Samba School Imperial State Crown of Great City for the 2016 carnival parade. The partner of Labsol and Crown Imperial brought to Labsol members to reflect on the role of design and the designer 
has allowed a rare university experience, covering the design education, design activity (in a dimension that came from brainstorn to series production) research, shipping materials, processes and methods and university extension, approaching the public university and the community that maintains it.

Keywords: Clothing Design, Sustainability, Carnival, Labsol

\section{INTRODUÇÃO}

O Grêmio Recreativo Escola de Samba Coroa Imperial da Grande Cidade, fundado em 1992, é uma escola de samba movida por um grupo familiar tradicional do bairro Núcleo Residencial Presidente Geisel em Bauru. A família, a escola e o bairro são tão orgânicos e naturais uns ao do outro, que suas histórias se confundem e se constroem mutuamente.

O convite para participar do carnaval da Coroa Imperial partiu de uma iniciativa de um outro projeto de Instituição de Ensino Superior, o Neocriativa, Núcleo de Estudos e Observação em Economia Criativa e também da insistência da Prof.a Dr.a Ana Beatriz Andrade em que a escola de samba procurasse o Labsol, por ter conhecimento do trabalho que o grupo desenvolve com comunidades e de sua experiência com as questões da cultura popular, já aventando a possibilidade de se criar um desfile de carnaval a partir de materiais reciclados.

A aproximação com a escola de samba se deu em julho de 2013, através de contato direto com a líder comunitária e diretora da escola, Olivia Arantes de Souza, àquela altura, a escola se encontrava desarticulada devido a problemas com recursos e com um carnavalesco pouco eficaz que cobrava absurdos pelos seus serviços criativos.

A proposta de trabalhar junto a escola foi levada ao conjunto de integrantes do Labsol, em agosto de 2013. O projeto já possuía alguma experiência com festas populares, pois durante seis anos participou da elaboração de um tapete de Corpus Christi na cidade de São Manuel SP, apoiando a ACAPEL - Associação de Catadores de Recicláveis de São Manuel - esta experiência era muito cara ao Labsol, entendendo que além de promover a inserção social dos associados que a constituíam, oportunizava uma imersão no questionamento sobre o papel do Trabalho na sociedade, de modo a subverter a ótica do Capital, uma vez que o trabalho não objetivava ganhos materiais, mas era realizado pelo simples prazer intrínseco da sua execução. Esta reflexão e o êxito do Labsol em São Manuel, na promoção social e na construção de uma identidade para o grupo de catadores e assim como sua inserção social em uma atividade das elites sociais da comunidade foi a maior motivação para que o Labsol assumisse o novo trabalho.

\section{DESENVOLVIMENTO}

\subsection{Laboratório de Design Solidário}

O LabSol (Laboratório de Design Solidário), é um projeto de Extensão Universitária do Departamento de Design, da Instituição de Ensino Superior, que, desde 2007, visa atender comunidades de baixa renda que tem no artesanato sua forma básica de subsistência. A proposta central é a promoção de ações conjuntas entre o design e o patrimônio cultural do artesanato, preocupando-se com a 
qualificação do produto artesanal e sua inserção no mercado a partir do tripé conceitual: Sustentabilidade (MANZINI, 2002), a Economia Solidária (SINGER, 2002) e o Ecodesign (BREZET, 1997), atendendo, numa relação dialógica (FREIRE, 1987) grupos de artesãos e comunidades, objetivando a geração de trabalho e renda, a fim de promover a autossustentabilidade de grupos produtores de artefatos.

O projeto é composto atualmente por alunos dos cursos de Design: bolsistas do CNPq em iniciação científica, da Instituição de Ensino Superior, e do Programa de Permanência Estudantil da Instituição de Ensino Superior, além de alunos e graduados que trabalham voluntariamente. Um dos objetivos que impulsiona o grupo é poder levar um Design de qualidade, à parcela da população que não teria acesso a este trabalho. Tem sido realizadas ações junto a comunidades e grupos cuja renda advém da produção artesanal.

O Labsol envolve os três aspectos da Universidade, para além da extensão universitária, contribuindo para a formação da cidadania em nossos alunos, desvinculando-se do capital internacional e produção em massa, e oferecendo apoio às comunidades, age também como laboratório didático e de pesquisa, tendo apresentado nos últimos anos dezenas de trabalhos científicos em congressos, ministrado oficinas de divulgação e realizado workshops, demonstrando desse modo a indissociabilidade do tripé ensino-pesquisa-extensão.

Nestes oito anos de existência, o Labsol tem desenvolvido uma grande quantidade de conhecimentos novos, tanto na criação de novos produtos, quanto no desenvolvimento de métodos e técnicas em Design Social. Atendeu dezenas de comunidades e produziu mais de cem protótipos de novos produtos e processos de produção, apresentados a estas comunidades, afirmando que o Design pode estar a serviço de uma sociedade mais sustentável, justa e igualitária.

\subsection{Parceria Coroa Imperial - LabSol - o início}

A princípio pensava-se em trabalhar com materiais já tradicionalmente recicláveis, mas a visita ao depósito da escola de samba fez com que se abandonasse a premissa de projeto, pois neste depósito existia uma enormidade de materiais usados: fantasias, saias de carros, e mesmo com muito material novo não utilizado - pelos carnavalescos anteriores. Assim as o Labsol se propôs a trabalhar a partir daquela "sucata".

Fez-se então uma coleta daquilo que parecia mais abundante na confusão daquele depósito. A ajuda da diretora da escola foi essencial nesta coleta, uma vez que ela era a única pessoa que sabia, ainda que por alto, o que havia naquele local.

Assim, faltando pouco mais de cinco meses do carnaval, foram montadas duas equipes de trabalho, uma para arrumar o depósito, separando fantasias e materiais e outra para o desenvolvimento das fantasias com fichas técnicas e peças piloto, alegorias, carros e destaques. O Labsol se propôs - e cumpriu - a desenvolver este trabalho, antes do início das férias escolares, ou seja, em pouco mais de dois meses, entretanto os integrantes do laboratório se sentiram extremamente motivados pelo desafio projetual proposto.

Enquanto se organizava o depósito com ajuda da comunidade e através da "dissecação" das fantasias existentes o Labsol pode compreender como eram executadas, entendeu que uma parte delas é construída a partir de costura - o que exige expertise e possui um custo mais elevado e que sua execução deveria ser terceirizada - e outra que tem sua base constituída por: plástico corrugado de polipropileno alveolar (polionda) que aramado possibilita a manutenção de formas e 
estruturas, tecido de nylon dublado estruturado por Etaflon laminado na espessura de $2 \mathrm{~mm}$, TNT, e o grampo de papel e, principalmente, o adesivo termoplástico como elementos de fixação.

O acabamento final, que os membros da comunidade costumam denominar de "materiais de brilho": galão de metalóide, o aljofre, chatons de acrílico, cordões de lantejoulas, acetato laminado metalizado vácuo formado, etaflon dourado, além de tecidos mais tradicionais como as rendas, cetins, brocados, paetês e falsos paetês. Para a estrutura de costeiros (alegoria que carregada às costas dos integrantes do desfile) eram utilizados arame galvanizado e vergalhões de aço de pequena bitola $7 X 20$ (ferro de estribo)

Assim de posse destas informações, com pilhas de fantasias antigas e tendo em mão o enredo "Entre Ícaro e a Lua, os Sonhos!" que tratava do sonho humano de voar, deu-se início ao projeto. Pela exigüidade do tempo foi proposto que trabalhassem com o material existente e a partir dos repertórios já constituídos pelos membros do Labsol.

A grande maioria dos projetos foi feita coletivamente, definiu-se uma palheta de cores, a partir da compreensão que a escola de samba deveria ser tratada como um grande objeto de comunicação visual em movimento,

Para cada fantasia e alegoria, foi realizado um "brainstorm", que resultava num projeto imediatamente prototipado, neste processo de prototipagem permitia avaliar a execução e alterar o projeto, ou seja, o processo de prototipagem era realmente uma etapa do projeto, entendia-se que o processo projetual só terminaria ao ser apresentado e discutido com a comunidade e a partir da resposta obtida se elaboraria a peça piloto final.

Depois de discutida com a comunidade e era elaborada a peça piloto, acompanhada de ficha técnica e por um conjunto de moldes em material plástico rígido - algumas peças foram objeto de workshops junta a comunidade - entendendo que estas peças seriam produzidas em série, onde cada atividade deveria despender 0 menor tempo e o melhor aproveitamento de recursos.

Além das fantasias de destaque, e do projeto dos carros alegóricos (alegorais) foram projetadas fantasias para 12 alas, incluindo a fantasia para a bateria e para a Comissão de Frente. Todo projeto desenvolvido pelo Labsol teve a preocupação com a reutilização máxima dos materiais e estruturas já existentes na comunidade, e por material reciclável.

Demonstrando ser possível fazer um desfile de carnaval com desenvolvimento de fantasias atrativas com um orçamento reduzido, utilizando materiais recicláveis e reutilizáveis, através do design e ações sustentáveis de forma estratégica e a execução das fantasias foi simplificada ao máximo tendo em vista o pouco tempo que a comunidade dispunha para executá-las.

Diferentemente das fantasias de ala que seriam produzidas em série a maioria dos destaques, que são peças únicas, tiveram um processo diferente, foram trabalhados artesanalmente, ou seja a partir do acervo de materiais e fantasias de outros carnavais e um croqui rápido dava início à construção destas fantasias.

Ao trabalhar junto a Comunidade da Coroa Imperial pode-se observar muitos fatos que fazem refletir sobre a relação entre o Design (erudito) e a cultura popular. A comunidade simplesmente perdeu todas as fichas técnicas e grande parte dos moldes, entregues junto as peças piloto. Desta aparente displicência percebeu-se que para eles, a ideia do projeto, não se transmite a partir do registro gráfico, assim os moldes e fichas técnicas não tinham muito significado, assim como preferiam recortar as peças 
individualmente (com grande desperdício de material e de tempo) e mesmo executar as fantasias uma a uma, ou seja, questões como o processo de produção em série eram bastante estranhas à comunidade.

Somente ao se entender que todo o processo de construção da cultura popular se faz por meio da tradição oral, e passar a demonstrar como eram feitas as fantasias, executando peças junto com as pessoas que executariam realmente as fantasias - tal como nossas avós ensinariam a fazer um bolo - demonstrando que ao se dobrar os materiais, ou colocá-los em camadas cortando diversas peças de uma só vez se ganhava tempo, mostrando como era importante a ficha técnica na quantificação das compras de material, e que separando a construção das fantasias em etapas e é que o processo de apreensão do projeto se deu.

O trabalho junto a este grupo de economia criativa, possibilitou aos alunos do Curso de Design uma experiência única e a reflexão sobre as questões básicas do conceito Trabalho, o Trabalho junto a Escola de Samba possibilita a subversão da ótica do Capital, uma vez que todo o trabalho na sociedade capitalista é transformado em mercadoria, e a partir disto se estabelece condições de apropriação, pois este tipo de trabalho não é apropriado pelo Capital, os indivíduos envolvidos trabalham, e se reconhecem no trabalho pelo Trabalho, trabalha-se pelo prazer de vê-lo realizado.

Neste processo contou-se também com o trabalho voluntário do alunado do Curso de Design da Instituição de Ensino Superior, na experiência de projeto, execução de protótipos, pilotos e peças finais, propiciando o contado com a comunidade e demonstrando na prática o papel social e o valor do designer na sociedade contemporânea.

O GRES Coroa Imperial último colocado no carnaval de 2013, recebeu o terceiro lugar em 2014, após o desfile todas as fantasias foram recolhidas e guardadas pela comunidade - que já previa a sua reutilização - e a parceria Coroa Imperial-Labsol manteve-se para o desfile de 2015.

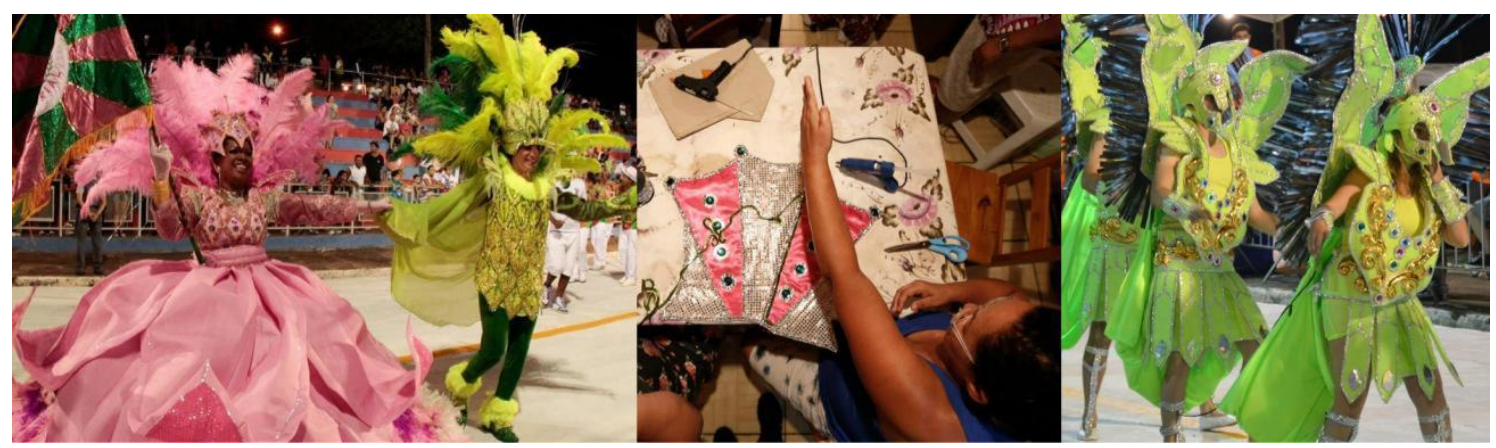

Figura 1 - Mestre-sala e porta-bandeira, comunidade confeccionando fantasias de ala, comissão de frente.

Fonte: Acervo Labsol.

\subsection{Carnaval 2015}

Os preparativos para o carnaval de 2015 começaram muito mais cedo do que no ano anterior, o desenvolvimento dos projetos e peças pilotos mantiveram-se como no ano anterior, talvez até com maior agilidade uma vez que já se dominava métodos e processos, e já éramos conhecidos pela comunidade, assim o processo projetual conjunto foi muito mais ágil a maior modificação foi na maneira que os projetos foram transmitidos. 
Cada peça piloto foi acompanhada de uma ficha técnica, e seus moldes em material plástico rígido, e foi exaustivamente explicado para a comunidade que a ficha técnica permitia calcular quanto de material seria usado em cada ala, e que os moldes rígidos ajudariam muito na confecção das fantasias. Por iniciativa da comunidade foi feito um gancho na parede onde todas as fichas e moldes foram afixados para que não se perdessem. Cada uma das peças pilotos foi exaustivamente explicada a comunidade e algumas foram objeto de workshops para ensinar como melhor executá-la, entendendo que estas peças seriam produzidas em série, onde cada atividade deveria despender o menor tempo e o melhor aproveitamento de recursos. Outra mudança foi que todas as fantasias foram feitas em um só local, sempre com a supervisão de algum membro do Labsol. A Coroa Imperial encontrou na universidade um caminho para desenvolver seu Carnaval, o que propiciou uma troca mútua de conhecimentos, técnicas e habilidades dos processos criativos. Entre outros frutos, a parceria proporciona a formação dos alunos para além da sala de aula,com espaço para o desenvolvimento das questões sociais e políticas, cumprindo assim com uns dos mais importantes papeis da Universidade Pública.

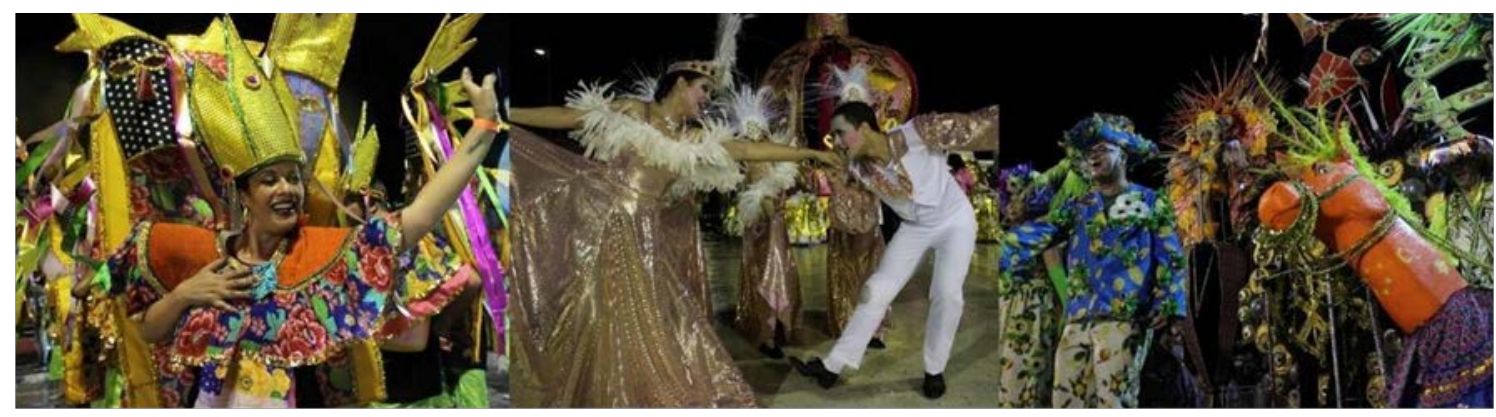

Figura 2 - Desfile no sambódromo - ala Folia de Reis; Comissão de frente e destaques do Carro alegórico Bumba Meu Boi.

Fonte: Acervo Labsol.

\subsection{Carnaval 2016}

A parceria em seu terceiro ano, pode se valer do acúmulo de aprendizado dos anos anteriores. Para cometer erros anteriores e otimizar o processo de produção, foi concebida a sistemática de trabalho que será descrita a partir desse ponto do artigo.

Fatos alheios à parceria, a falta de capacidade administrativa dos dirigentes da Coroa Imperial, tanto no gerenciamento dos recursos advindos da Prefeitura Municipal através da Secretaria da Cultura do Município de Bauru, tanto na sua ineficácia em captação de recursos externos ou na geração de recursos próprios através de festas, que são uma fonte tradicional na obtenção de recursos nas escolas de samba, o desfile de carnaval de 2015 deixou a Coroa Imperial endividada, o que foi agravado pelo descuido dos dirigentes com os geradores de energia alugados que foram furtados logo depois do desfile. Entretanto, a quase totalidade das fantasias foram resgatadas logo após o desfile, o que possibilitaria a reutilização de seus materiais e componentes, demonstrando que a escola de samba havia absorvido os conceitos de reciclagem e reutilização apresentados pelo Labsol.

Se as fantasias foram recuperadas por outro lado os carros alegóricos foram abandonados, e grande quantidade de material que poderia ser reutilizado perdeu-se por serem abandonados ao tempo. Assim novamente a Coroa Imperial necessitava de 
um desfile de baixo custo e o primeiro enredo elaborado que deveria tratar de fé foi descartado.

Algumas premissas iniciais de projeto foram estabelecidas, além da reciclagem máxima de fantasias, os carros não seriam iluminados, deveriam ter pouco trabalho de serralheria mantendo as estruturas anteriores.

O novo enredo foi escolhido fazendo uso da técnica "brainstorm". Dessa reunião fizeram parte membros da Escola de Samba, entre comunidade e diretoria, e membros do projeto LabSol, do enredo anterior foram mantidos dois carros, o carro sobre o barroco e seus santos aproveitando reciclando destaques do carnaval de 2015 e o carro dos orixás, este principalmente por ser a Coroa Imperial uma escola de matriz negra que o Labsol desde o primeiro enredo procura ressaltar, enquanto projeto de extensão comprometido socialmente, procura resgatar e projetar a identidade e a cultura das comunidades atendidas, sendo essa uma das preocupações adotadas no desenvolvimento do enredo para os anos da parceria a valorização das pessoas de cor da pele negra e de sua cultura, promovendo a elevação de sua autoestima.

As fantasias do ano anterior com muitos babados e a utilização do tecido de chita indicavam a possibilidade do uso de muita cor, assim como algumas estruturas de adorno de cabeça poderiam ser usadas para a construção de fantasias de indígenas. Assim seria fácil falar sobre a construção do povo brasileiro, mas que não traria nada de novo ao carnaval bauruense.

Assim o enredo escolhido procurou então versar sobre a América Latina, emergindo da noção de que o Brasil acaba se isolando do restante do continente, esquecendo-se de olhar mais para os nossos vizinhos de continente. A princípio o enredo seria "Soy loco por ti América", entretanto o pouco numero de alas, apenas 10 pela falta de recursos, foi substituído por "América - Mestiça, Mãe - Terra" e procuraria abranger os povos que construíram este continente e as suas diversas regiões etno-geográficas.

Uma importante prerrogativa do tema escolhido foi a possibilidade que ele confere ao reaproveitamento dos materiais de fantasia, bem como dos carros alegóricos, novamente buscando equalizar os recursos financeiros de que a escola de samba dispunha.

Procurando evitar este acomodamento o Labsol propôs-se a executar as peças piloto de alas, ministrar workshops de sua construção, mas, não se envolver na produção destas fantasias, assim como eximiu-se de dar o acabamento nos carros alegóricos ainda que executasse algumas de suas esculturas, ficando outras e o acabamento a cargo da escola.

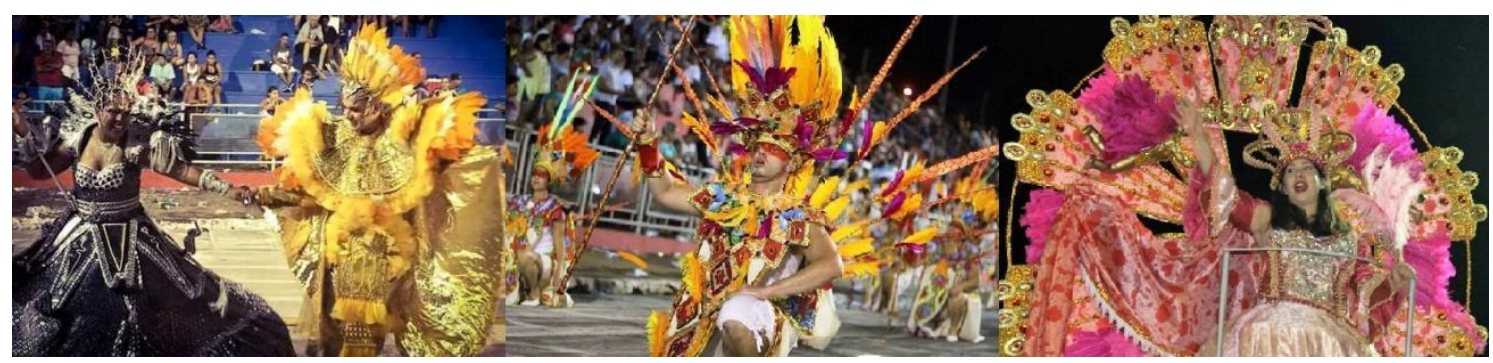

Figura 3 - Mestre e sala e porta-bandeira se apresentando, ala coreografa e destaque Nossa Senhora da Conceição, do carro Barroco.

Fonte: Acervo Labsol. 


\section{CONCLUSÃO}

A parceira do Labsol e a Coroa Imperial trouxe aos integrantes do Labsol a reflexão sobre o papel do Design e do designer permitiu uma rara experiência universitária, abarcando o ensino de design, a atividade projetual (em uma dimensão que partiu do brainstorn à produção em série) atividades de pesquisa, embarcando materiais, processos e métodos e a extensão universitária, aproximando a Universidade Pública e a Comunidade que a mantém.

Permitiu refletir sobre questões de metodologia de projeto e na sua representação, uma vez que foi necessário a adaptar a transmissão dos projetos pelo discurso oral visto que os integrantes da comunidade pareciam não compreender moldes, fichas técnicas e peças piloto, ainda que em outros carnavais tivessem feito fantasias muito mais complexas e elaboradas.

Permitiu também uma reflexão sobre o papel social do design como agente da mudança social tomando a si, e compartilhando com a Comunidade da Coroa Imperial, a responsabilidade quanto ao desenvolvimento sustentável, o prolongamento do ciclo de vida útil dos materiais, a reciclagem e reutilização.

\section{REFERÊNCIAS}

BAXTER, Mike. Projeto de Produto, Guia prático para o design de novos produtos.

Tradução Itiro lida. Editora Blucher, 2011.

BORGES, Adélia. Design+Artesanato. São Paulo: Terceiro Nome, 2011

BREZET, H. VAN HEMEL, C. BÖTTCHER, H. CLARKE, R. Ecodesign: a promising approach to sustainable production and consumption: UNEP, 1997.

FREIRE, Paulo. Pedagogia do oprimido. 17ạ edição, Paz e Terra, Rio de Janeiro, 1987.

GOYA, C. R.; ANDRADE, A. B. P.; DOMICIANO, C. L. C.; ROSSI, D. C.; MEDOLA; F. O.; HENRIQUES, F, SILVA, J. P. C., PASCHOARELLI, L. C.; MOURA, M.; RODRIGUES, O. V.; BIGAL, S. M.; BARATA, T. Carnaval, Cultura Popular e Design - Uma Experiência de Extensão Universitária em Design In: Ensaios em Design - Práticas Interdisciplinares.1 ed. Bauru: Canal 6 Editora, 2014, p. 136-156.

MANZINI, Ezio; VEZZOLI, Carlo, trad. CARVALHO, Astrid de. O Desenvolvimento de Produtos Sustentáveis: os requisitos ambientais dos produtos industriais. São Paulo: EDUSP, 2002.

RIBEIRO, Darcy. O Povo Brasileiro - A Formação e o Sentido do Brasil. São Paulo: Companhia das Letras, 1995.

SINGER, Paul. Introdução à Economia Solidária. São Paulo: Fundação Perseu Abramo, 2002. 